\title{
Trocas gasosas de mudas de videira, obtidas por dois porta-enxertos, submetidas à deficiência hídrica ${ }^{(1)}$
}

\author{
Claudia Rita de Souza(2), Ângela Maria Soares ${ }^{(3)}$ e Murillo de Albuquerque Regina(4)
}

\begin{abstract}
Resumo - Este trabalho teve como objetivo avaliar o efeito da deficiência hídrica e de dois portaenxertos nas trocas gasosas de mudas de videira cultivadas em vasos, nas condições de casa de vegetação. Utilizou-se como copa a 'Niágara Rosada' (Vitis labrusca), e como porta-enxertos, o 101-14 (V. riparia) e o 1103 Paulsen (V.rupestris x $V$. berlandieri). Doze dias após a suspensão da rega, o potencial hídrico foliar da combinação 'Niágara Rosada'/101-14 apresentou os menores valores (-2,80 MPa) em relação à 'Niágara Rosada'/1103 Paulsen (-2,10 MPa) nas plantas não-irrigadas, enquanto o teor relativo de água variou apenas entre os tratamentos hídricos. Com a evolução do estresse hídrico, houve uma sensível redução nas trocas gasosas da cultivar 'Niágara Rosada', que apresentaram valores próximos de zero, devido ao fechamento dos estômatos, sem diferenças entre os portaenxertos. Somente após 12 dias sem rega, os porta-enxertos influenciaram a eficiência no uso da água e eficiência fotoquímica do fotossistema II, onde a 'Niágara Rosada' enxertada sobre o 101-14 apresentou valores inferiores ao 1103 Paulsen. Entretanto, durante o período de suspensão da rega, os porta-enxertos não influenciaram as trocas gasosas da cultivar 'Niágara Rosada', e apresentaram comportamento semelhante em condições de baixa disponibilidade hídrica.
\end{abstract}

Termos para indexação: Vitis labrusca, deficiência hídrica, fotossíntese, fluorescência.

\section{Gas exchange of vine cuttings obtained from two graftings submitted to water deficiency}

\begin{abstract}
The present work aimed to evaluate the water deficiency effect and two graftings on the gas exchange of vine cuttings under greenhouse conditions. 'Niágara Rosada' (Vitis labrusca) was used as scion, and 101-14 (V. riparia $\times$ V. rupestris) and 1103 Paulsen ( $V$. rupestris $\times$ V. berlandieri) were used as rootstocks. Twelve days after watering suspension, the leaf water potential of the combination 'Niágara Rosada'/101-14 showed lower (-2.80 MPa) in relation to 'Niágara Rosada'/1103 Paulsen (-2.10 MPa) in the non-irrigated plants, while relative water content altered only among watering levels. With the progress of water stress, there was a marked reduction in the gas exchange of the cultivar "Niágara Rosada', which presented values close to zero, due to stomatal closure, without differences among the rootstocks. Only after twelve days without water the rootstocks influenced water use efficiency and photochemical efficiency of photosystem II, where the combination 'Niágara Rosada'/101-14, presented lowest values to 1103 Paulsen. However, during water removal, the rootstock did not influence gas exchange of the 'Niágara Rosada', showing the same behavior in water deficiency.
\end{abstract}

Index terms: Vitis labrusca, water deprivation, photosynthesis, fluorescence.

(1) Aceito para publicação em 10 de novembro de 2000 Extraído da Dissertação de Mestrado apresentada pela primeira autora à Universidade Federal de Lavras (Ufla), Lavras, MG

(2) Instituto de Tecnologia Química e Biológica, Av. da República, Apartado 127, CEP 2780-901 Oeiras, Portugal. E-mail: souza@itqb.unl.pt

(3)Ufla, Dep. de Biologia, Caixa Postal 37, CEP 37200-000 Lavras, MG. E-mail: amsoares@ufla.br

(4)Empresa de Pesquisa Agropecuária de Minas Gerais, Fazenda Experimental de Caldas, Caixa Postal 33, CEP 37780-000 Caldas, MG. E-mail: mregina@pcs.matrix.com.br

\section{Introdução}

De todos os recursos de que as plantas precisam para o crescimento, a água é o mais limitante para a produtividade agrícola, visto ser essencial aos diversos processos metabólicos das plantas, principalmente durante o período inicial de desenvolvimento.

Uma das primeiras respostas das plantas à deficiência hídrica é o fechamento dos estômatos, e com isto, a diminuição da difusão de $\mathrm{CO}_{2}$ para o mesófilo 
foliar, o que causa a queda na fotossíntese. Nos últimos anos, têm sido realizados diversos trabalhos que evidenciam diferenças varietais na regulação da atividade fotossintética em situação de estresse, permitindo que avaliações fisiológicas, como as medidas de trocas gasosas, possam ser utilizadas para discriminar cultivares de videira quanto à resistência ao déficit hídrico (Chaves, 1986; Chaves \& Rodrigues, 1987; Chaves et al., 1987; During, 1987; Nagarajah, 1989; Winkel \& Rambal, 1993; Poni et al., 1994; Regina \& Carbonneau, 1996; Schultz, 1997).

Além do comportamento varietal, as diferentes combinações de porta-enxerto e copa revelam comportamentos característicos em relação às trocas gasosas e hídricas de videira, afetando o grau de tolerância à seca, uma vez que o comportamento fisiológico da parte aérea pode ser afetado pelo genótipo do porta-enxerto (Scienza et al., 1980; Carbonneau, 1985; Iacono et al., 1998). A influência dos portaenxertos sobre a copa pode ocorrer por mudanças no balanço hormonal, na absorção de água e no potencial hídrico foliar (Candolfi-Vasconcelos et al., 1994).

Sob deficiência hídrica, a interação entre portaenxerto e copa pode se tornar mais significativa. As diferenças na capacidade do sistema radicular dos porta-enxertos em absorver água pode ser responsável pelas variações no grau de tolerância à seca da cultivar copa (Carbonneau, 1985). De acordo com Mottard et al. (1963), Scienza et al. (1980) e Carbonneau (1985), o porta-enxerto 1103 Paulsen é caracterizado como mais tolerante à seca que o 101-14. Desta forma, determinadas interações entre porta-enxerto e variedade produtora podem induzir a um melhor desempenho da cultivar copa em situação de estresse hídrico, o que pode ser vantajoso no plantio de vinhedos em região de seca prolongada.

O objetivo deste trabalho foi avaliar as trocas gasosas de plantas de videira (Vitis labrusca), cultivar 'Niágara Rosada', enxertadas sobre diferentes porta-enxertos, submetidas à deficiência hídrica.

\section{Material e Métodos}

Este trabalho foi conduzido durante o período de janeiro a março de 1999, em casa de vegetação, da Empresa de Pesquisa Agropecuária de Minas Gerais (Epamig), em
Lavras. Para as avaliações de resposta ao déficit hídrico, foram utilizadas mudas enxertadas, obtidas pelo método de enxertia de mesa com forçagem, empregando-se como variedade copa a 'Niágara Rosada' (Vitis labrusca), e como porta-enxertos, o 1103 Paulsen ( $V$. berlandieri $\mathrm{x}$ $V$. rupestris), e o 101-14 (V. riparia $\mathrm{x} V$. rupestris). A seleção dos porta-enxertos baseou-se no interesse agronômico, uma vez que estão entre os porta-enxertos mais utilizados na viticultura brasileira, e nas informações sobre tolerância à seca.

As mudas com idade de seis meses foram plantadas em vasos de plástico de 8 litros contendo como substrato uma mistura de Latossolo Vermelho-Escuro (LVE), distrófico, textura argilosa, esterco de curral e areia, na proporção 2:1:1. Até o início da imposição do estresse hídrico, as plantas foram adubadas diariamente com uma solução nutritiva, de acordo com as necessidades da cultura (Pouget, 1984).

No momento em que as plantas atingiram um tamanho aproximadamente de $1 \mathrm{~m}$, foram iniciados os tratamentos hídricos, que consistiram em rega diária das plantas, mantendo, assim, o teor de água no solo próximo à capacidade de campo, e plantas submetidas a deficiência hídrica, por meio da suspensão total da rega.

Durante o período experimental, foram realizadas avaliações do potencial hídrico foliar máximo, medido antes do amanhecer (5h30), e do teor relativo de água (TRA). O potencial hídrico foliar máximo foi medido com auxílio de uma bomba de pressão (Soil-Moisture - Modelo 3005$)$.

O teor relativo de água foi obtido a partir das mesmas folhas empregadas nas avaliações do potencial hídrico foliar. Para evitar a perda de água das folhas após a medida do potencial hídrico, elas foram embrulhadas em papel-alumínio e mantidas em caixa de isopor com gelo até a retirada dos discos foliares. Amostras compostas de sete discos foliares com $0,6 \mathrm{~cm}$ de diâmetro foram retiradas do centro do limbo foliar, evitando as nervuras, e imediatamente pesadas, obtendo-se a massa da matéria fresca (MF). Em seguida, os discos foram submersos em água destilada, para atingirem a saturação hídrica. Após 24 horas, período estabelecido a partir de testes preliminares, os discos foliares foram retirados da água, eliminando-se o excesso de água com auxílio de papel absorvente, e pesados imediatamente para a determinação da massa túrgida (MT). Posteriormente, obteve-se a massa seca (MS), através da secagem em estufa (em torno de $70^{\circ} \mathrm{C}$ ) até atingirem massa constante. $\mathrm{O}$ teor relativo de água foi calculado segundo a fórmula: TRA = 100[(MF-MS)/(MT-MS)]. Em função do caráter destrutivo destes métodos, e das poucas plantas disponíveis, somente duas medições fo- 
ram efetuadas nas plantas: a primeira, após nove dias de suspensão da rega, e a segunda, ao final do experimento.

As medições de trocas gasosas foram realizadas periodicamente, com um analisador portátil de $\mathrm{CO}_{2}$ a infravermelho (IRGA), modelo ADC-LCA4 (Hoddesdon, UK). Foram avaliadas as seguintes características: taxa de fotossíntese (A), transpiração (E), condutância estomática $(\mathrm{g})$, concentração de $\mathrm{CO}_{2}$ intracelular $(\mathrm{Ci})$, densidade de fluxo de fótons fotossinteticamente ativos (DFFFA), temperatura da folha (Tf), temperatura $(\mathrm{T})$ e umidade relativa do ar na câmara (UR). Através dos valores de Ci, A e E, foram calculadas a eficiência do uso da água e a eficiência de carboxilação, definidas pelas razões $\mathrm{A} / \mathrm{E}$ e $\mathrm{A} / \mathrm{Ci}$, respectivamente. A partir dos dados de umidade relativa e temperatura da cubeta, foram obtidos os valores do déficit de pressão de vapor da atmosfera. As avaliações foram feitas às $9 \mathrm{~h}$ e $12 \mathrm{~h}$ (hora solar), sempre nas mesmas folhas adultas e sadias, previamente escolhidas no terço médio do ramo de cada planta. Foram escolhidos os dois horários por representarem períodos de diferentes demandas atmosféricas, permitindo, assim, eliminar os possíveis efeitos limitantes do horário das doze horas sobre os tratamentos.

Com auxílio de um fluorômetro portátil (Plant Efficency Analyser, Hansatech, King's Lynn, Nor Kfolk, UK), foi medida a máxima eficiência fotoquímica do fotossistema II, através da razão Fv/Fm, em que Fv é a fluorescência variável, e Fm a fluorescência máxima. A medição da fluorescência rápida in vivo foi realizada após 30 minutos de adaptação das folhas no escuro. $\mathrm{O}$ escurecimento da folha foi realizado com grampos de metal, que foram fixados nas folhas, impedindo a incidência de luz. Estas medidas foram realizadas às $9 \mathrm{~h}$ e $12 \mathrm{~h}$, nas mesmas folhas utilizadas para as medições de trocas gasosas.

$\mathrm{O}$ delineamento experimental foi o inteiramente casualizado em esquema fatorial $2 \times 2$, correspondendo a dois porta-enxertos e dois tratamentos hídricos, com quatro repetições por tratamento, representadas por uma a duas folhas por planta, e a parcela experimental constituída de três plantas por parcela. Para as avaliações do potencial hídrico e teor relativo de água, as médias foram obtidas de três repetições, sendo retirada uma folha de cada planta.

\section{Resultados e Discussão}

As avaliações de potencial hídrico foliar da 'Niágara Rosada', nove dias após a suspensão da rega, revelaram diferenças significativas $(\mathrm{p}<0,05)$ entre os tratamentos hídricos (Tabela 1). As plantas sob defi- ciência hídrica atingiram $-0,9 \mathrm{MPa}$, e as irrigadas diariamente, $-0,3 \mathrm{MPa}$, independentemente do portaenxerto utilizado, enquanto o teor relativo de água permaneceu constante entre os tratamentos.

Após 12 dias sem rega, o potencial hídrico das plantas reduziu de $-0,3 \mathrm{MPa}$ para valores inferiores a -2 MPa, podendo ser observadas diferenças significativas $(p<0,05)$ nos porta-enxertos. Foram registrados potenciais hídricos de $-2,13 \mathrm{MPa}$ para 'Niágara Rosada'/1103 Paulsen, e -2,80 MPa para 'Niágara Rosada'/101-14. Estes valores permitem caracterizar as mudas em condições de estresse severo, conforme foi observado por Nagarajah (1989). Resultados nesta faixa de valores eram esperados, uma vez que resultaram da avaliação de mudas em vasos com suspensão total da rega. As variações nos valores de potencial hídrico entre os porta-enxertos estão de acordo com informações na literatura em que o porta-enxerto 1103 Paulsen consegue manter o potencial hídrico mais elevado em algumas cultivares de videira (Scienza et al., 1980).

Em relação ao teor relativo de água, as plantas somente manifestaram diferenças significativas $(\mathrm{p}<0,05)$ entre os tratamentos hídricos, sendo verificados $94,8 \%$ e $74,1 \%$ nas plantas irrigadas e nãoirrigadas, respectivamente. Estes resultados foram semelhantes ao obtido por Schultz (1997), que verificou diferenças no potencial hídrico de cultivares de videira, sem ter ocorrido diferenças no teor relativo de água. Entretanto, deve ser considerado, ainda, que os resultados obtidos podem ter sofrido a influência de múltiplos fatores associados à metodologia de determinação desta medida (Sinclair \& Ludlow, 1985), o que pode ter contribuído para ausência de diferenças entre os tratamentos. Variações que ocorrem no tempo necessário para retirar os discos foliares das folhas e pesá-los, a forma como a folha foi acondicionada até o momento de sua pesagem, e ainda, a maneira como as folhas são secas após o período de saturação hídrica, são exemplos de possíveis fatores que podem interferir no teor de água das folhas durante a medição.

As Figuras 1 e 2 ilustram os resultados obtidos para as trocas gasosas nos horários de nove e doze horas, respectivamente, ao longo da evolução do regime de estresse hídrico. As oscilações observadas às nove horas, nas curvas de fotossíntese, condutância estomática e transpiração, acompanham as variações 
da radiação e déficit de pressão de vapor durante o período experimental. A taxa fotossintética variou de $6 \mathrm{a} 13 \mu \mathrm{mol} \mathrm{m} \mathrm{m}^{-2} \mathrm{~s}^{-1}$ durante o período da manhã, e às $12 \mathrm{~h}$, permaneceu ao redor de $10 \mu \mathrm{mol} \mathrm{m}^{-2} \mathrm{~s}^{-1}$ nas plantas irrigadas, valor normalmente observado na videira, na literatura (Koblet, et al., 1997; Regina \& Carbonneau, 1997; Schultz, 1997).

A partir do sétimo dia após a interrupção da rega, foram verificadas reduções significativas na fotossíntese $(\mathrm{p}<0,05)$ da cultivar 'Niágara Rosada' no horário das $12 \mathrm{~h}$. Neste período, a fotossíntese diminuiu aproximadamente em 50\% no tratamento nãoirrigado, independentemente do porta-enxerto. Reduções na transpiração, condutância estomática e $\mathrm{Ci}$, entre os tratamentos hídricos, ocorreram após nove dias de suspensão da rega, nos dois horários avaliados. A partir desta data, a transpiração e condutância estomática alcançaram valores próximos de zero, sem distinções entre os porta-enxertos.

O comportamento das trocas gasosas foliares da cultivar 'Niágara Rosada' não foi influenciado pelo porta-enxerto, tanto em condições irrigadas como não-irrigadas. As curvas de resposta da fotossíntese e transpiração, em relação ao tratamento de déficit hídrico, foram acompanhadas de reduções na condutância estomática, considerada uma das primeiras respostas ao déficit hídrico, para evitar a desidratação dos tecidos. Outra consequência do fechamento dos estômatos é a redução da concentração de $\mathrm{CO}_{2}$ intercelular, mas esta apresentou variações ao longo do período experimental, e não diminuiu com o fe- chamento dos estômatos. Esta resposta pode indicar que a fotossíntese reduziu também, devido a fatores não-estomáticos. Entretanto, esta afirmação pode não ser verdadeira, pois a concentração de $\mathrm{CO}_{2}$ intercelular pode ter sido superestimada durante as medições, devido ao fechamento não uniforme dos estômatos (Dowton et al., 1988).

Após sete dias sem rega, observou-se uma diminuição da taxa de assimilação líquida de $\mathrm{CO}_{2}$, que pode ser atribuída a uma limitação não-estomática, pois a condutância não variou entre os dois regimes de rega. Alguns estudos revelam que fatores nãoestomáticos, como por exemplo, redução da atividade e concentração da enzima Ribulose 1-5 bifosfato carboxilase oxigenase (rubisco), fotoinibição e redução da eficiência fotoquímica do fotossistema II, podem estar envolvidos na limitação não-estomática da fotossíntese (Chaves \& Rodrigues, 1987; Chartzoulakis et al., 1993; Patakas, 1993). Neste período, a eficiência de carboxilação da cultivar 'Niágara Rosada', em condições irrigadas, foi superior às das plantas estressadas, o que pode ter levado a um aumento da fotossíntese (Figura 3).

Quando o potencial hídrico atingiu valores inferiores a -2,0 $\mathrm{MPa}$, no décimo dia após a suspensão da rega, a fotossíntese diminuiu, em média, de $10 \mu \mathrm{mol} \mathrm{m} \mathrm{m}^{-2} \mathrm{~s}^{-1}$ nas plantas irrigadas para $0,8 \mu \mathrm{mol} \mathrm{m}{ }^{-2} \mathrm{~s}^{-1}$ nas plantas em déficit hídrico, nos dois horários avaliados. A redução nas trocas gasosas da 'Niágara Rosada' não foi diferenciada pelos porta-enxertos, nos dois tratamentos hídricos.

Tabela 1. Potencial hídrico foliar máximo e teor relativo de água de mudas de videira cultivar 'Niágara Rosada', sobre dois porta-enxertos, 9 e 12 dias após a suspensão da rega, em plantas irrigadas diariamente e não-irrigadas. Epamig, Lavras, MG, $1999^{(1)}$.

\begin{tabular}{|c|c|c|c|c|}
\hline \multirow[t]{2}{*}{ Porta-enxerto } & \multicolumn{2}{|c|}{ Potencial hídrico (-MPa) } & \multicolumn{2}{|c|}{ Teor relativo de água $(\%)$} \\
\hline & Irrigada & Não-irrigada & Irrigada & Não-irrigada \\
\hline & \multicolumn{4}{|c|}{9 dias } \\
\hline 1103 Paulsen & $0,30 \mathrm{aA}$ & $0,90 \mathrm{bB}$ & $94,84 \mathrm{aA}$ & $88,81 \mathrm{aA}$ \\
\hline $101-14$ & $0,36 \mathrm{aA}$ & $0,90 \mathrm{bB}$ & $89,49 \mathrm{aA}$ & $89,02 \mathrm{aA}$ \\
\hline \multirow[t]{2}{*}{ Média } & $0,33 \mathrm{a}$ & $0,90 \mathrm{~b}$ & $92,17 \mathrm{a}$ & $88,92 \mathrm{a}$ \\
\hline & \multicolumn{4}{|c|}{12 dias } \\
\hline 1103 Paulsen & $0,33 \mathrm{aA}$ & $2,13 \mathrm{bA}$ & $95,56 \mathrm{aA}$ & $77,84 \mathrm{bA}$ \\
\hline $101-14$ & $0,33 \mathrm{aA}$ & $2,80 \mathrm{bB}$ & $93,98 \mathrm{aA}$ & $74,12 \mathrm{bA}$ \\
\hline Média & $0,33 \mathrm{a}$ & $2,46 b$ & $94,77 \mathrm{a}$ & $75,98 b$ \\
\hline
\end{tabular}

${ }^{(1)}$ Médias seguidas de mesma letra, minúscula nas linhas e maiúscula nas colunas, não diferem entre si pelo teste de Tukey a 5\% de probabilidade. 
Os porta-enxertos 1103 Paulsen e o 101-14 induziram o mesmo comportamento na copa, tanto em condições irrigadas como em condição de estresse, durante este período.

$\mathrm{O}$ comportamento fisiológico quanto às trocas gasosas das folhas da videira neste experimento não foi afetado pelo porta-enxerto, ao contrário das informações existentes na literatura, que revelam res- postas diferenciadas da copa à progressiva redução hídrica do solo, em razão de determinadas combinações de enxertia segundo os resultados de Scienza et al. (1980) e Iacono et al. (1998). Entretanto, a metodologia empregada por estes autores para induzir o déficit hídrico difere da adotada neste experimento. Naqueles trabalhos, as plantas não foram submetidas a suspensão total da rega, e manteve-se uma

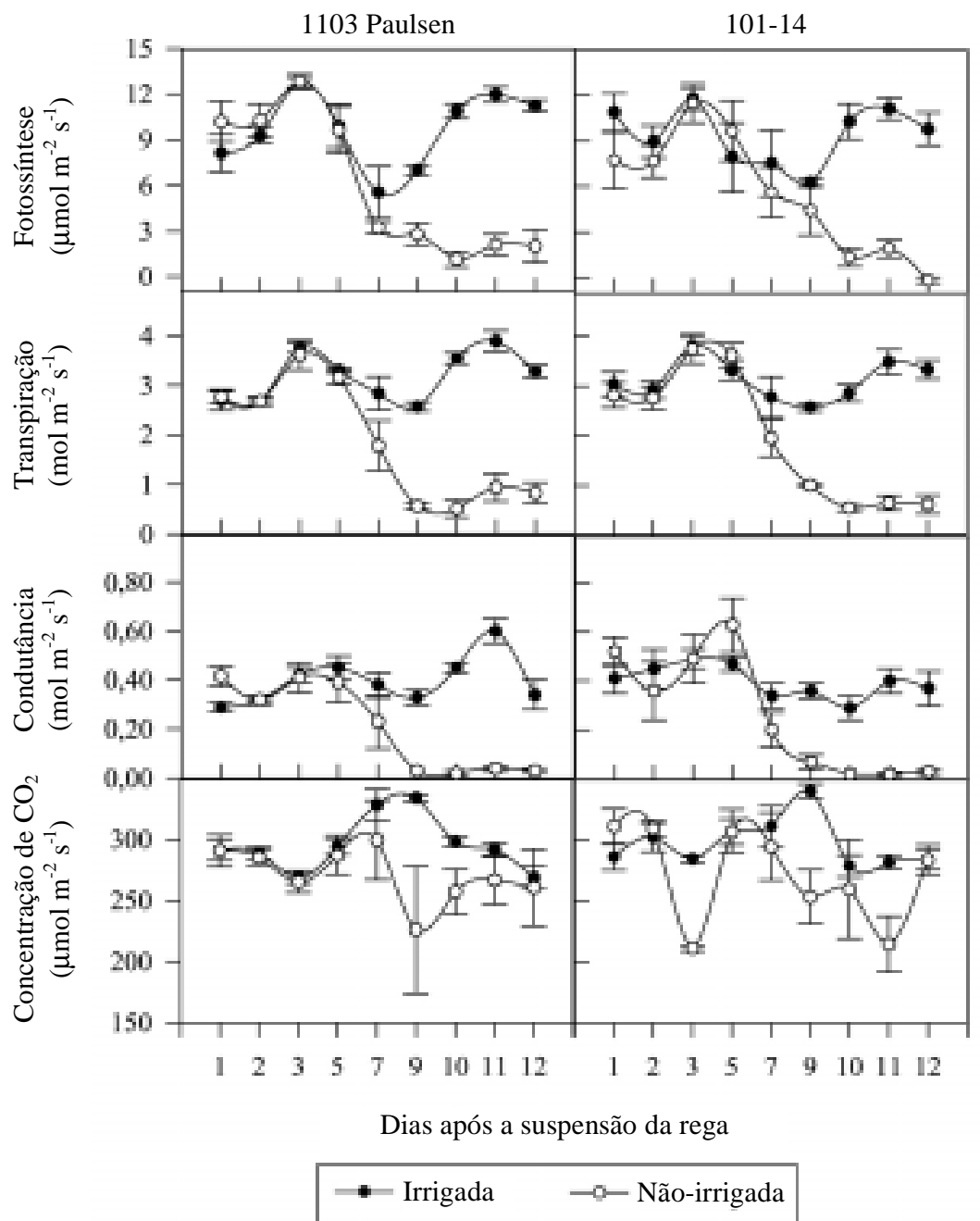

Figura 1. Fotossíntese, transpiração, condutância estomática e concentração de $\mathrm{CO}_{2}$ intracelular medidos às nove horas, em mudas de videira cultivar 'Niágara Rosada', sobre dois porta-enxertos, 1103 Paulsen e 101-14, durante a suspensão da rega, em plantas irrigadas e não-irrigadas. As barras de desvios representam o erro-padrão da média de quatro repetições. Epamig, Lavras, MG, 1999. 
quantidade mínima de água, o que pode ter contribuído para os diferentes resultados observados. Ressalta, ainda, que, em razão de determinadas combinações de enxertia, o porta-enxerto pode induzir a um comportamento diferenciado da copa às condições de deficiência hídrica. Assim, os porta-enxertos utilizados neste experimento, conhecidos pelo seu grau de tolerância à seca, podem não apresentar o mesmo potencial com distintas variedades copa.
A eficiência no uso da água (EUA) e a eficiência de carboxilação (A/Ci), no período de déficit hídrico, diminuíram com a redução das reservas hídricas no solo (Figura 3). Entretanto, as reduções foram mais visíveis para a eficiência de carboxilação. A partir do nono dia sem água, às $12 \mathrm{~h}$, foram observadas diferenças significativas $(p<0,05)$ entre os tratamentos hídricos, sem diferenças entre os porta-enxertos. Os valores diminuíram de $0,04 \mu \mathrm{mol} \mathrm{m} \mathrm{m}^{-2} \mathrm{~s}^{-1}$ nas plan-

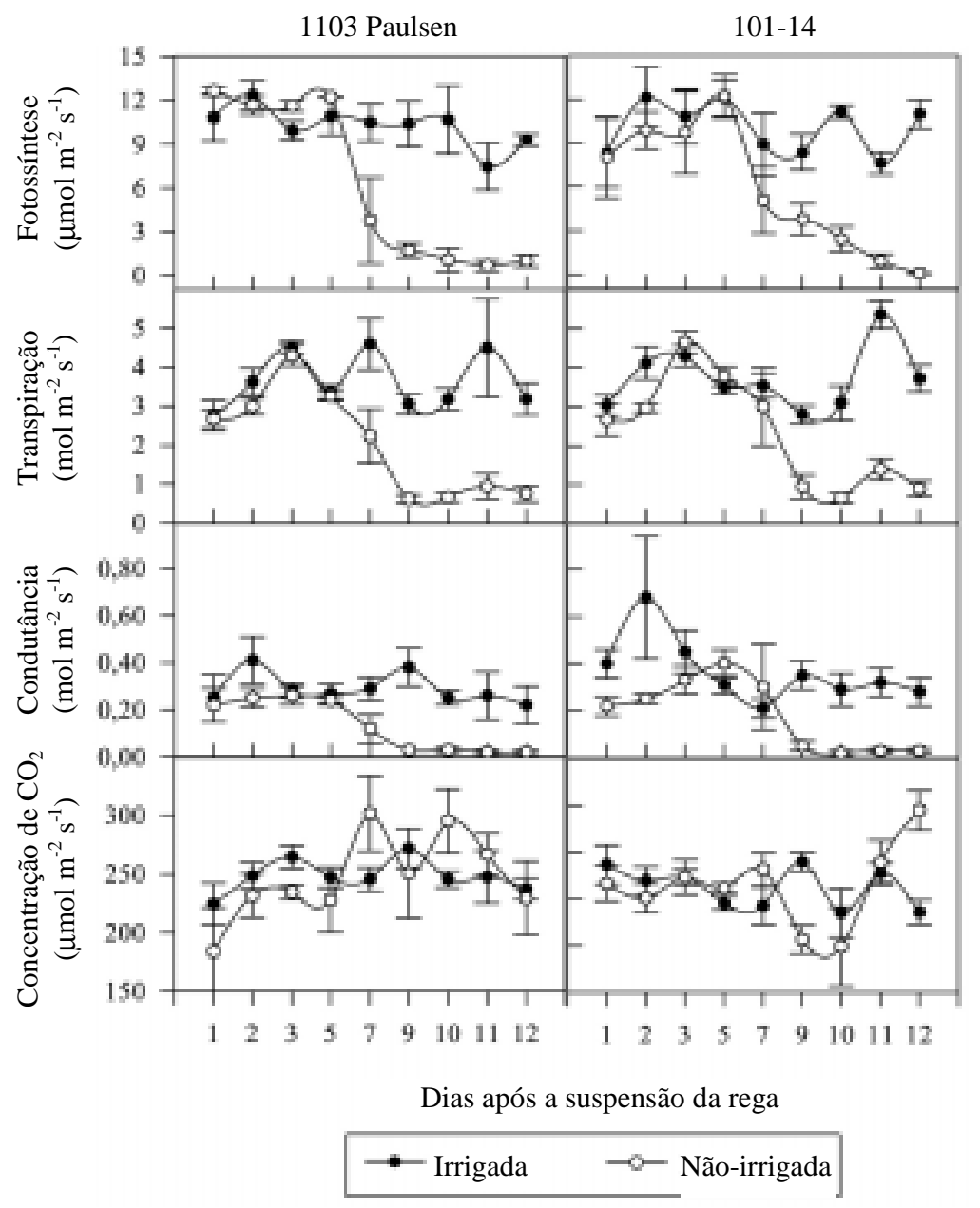

Figura 2. Fotossíntese, transpiração, condutância estomática e concentração de $\mathrm{CO}_{2}$ intracelular medidos às doze horas, em mudas de videira cultivar 'Niágara Rosada', sobre dois porta-enxertos, 1103 Paulsen e 101-14, durante a suspensão da rega, em plantas irrigadas e não-irrigadas. As barras de desvios representam o erro-padrão da média de quatro repetições. Epamig, Lavras, MG, 1999. 
tas irrigadas, a $0,01 \mu \mathrm{mol} \mathrm{m} \mathrm{m}^{-2} \mathrm{~s}^{-1}$ no tratamento não-irrigado. Desta forma, a redução da fotossíntese também pode ser atribuída a alterações na capacidade fotossintética do mesófilo foliar. Estas respostas podem ser atribuídas à redução na atividade da enzima rubisco, em virtude da sua menor concentra- ção ou perda de atividade enzimática, em condições de estresse hídrico, conforme revelaram Farquhar \& Sharkey (1982) e Chaves (1991).

Em relação às respostas das plantas associadas à eficiência no uso da água, estas não foram constantes durante o experimento, ou seja, as diferenças en-

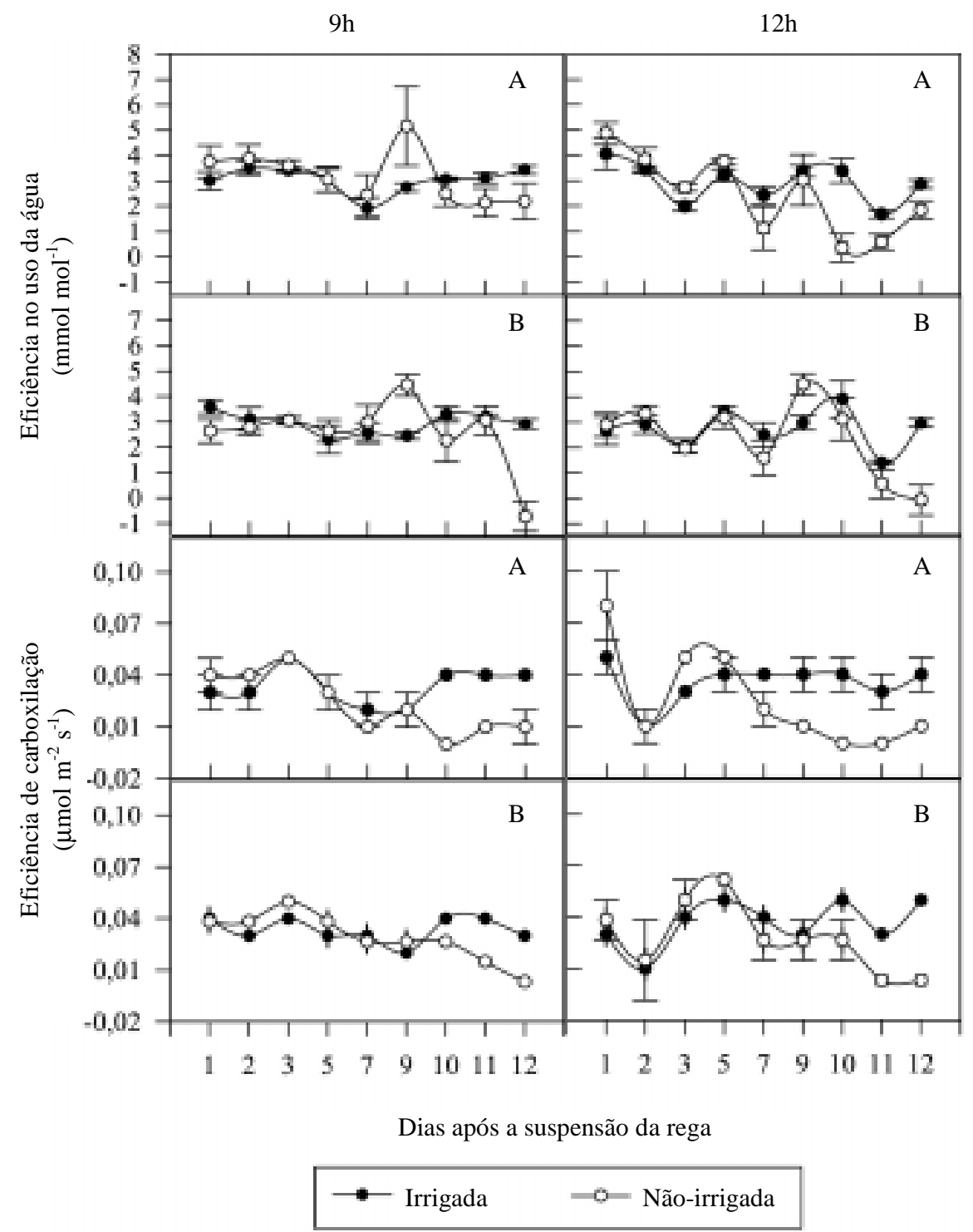

Figura 3. Eficiência de carboxilação e eficiência no uso da água nos dois horários de avaliação, em mudas de videira cultivar 'Niágara Rosada', sobre dois porta-enxertos, 1103 Paulsen (A) e 101-14 (B), durante o período de suspensão da rega, em plantas irrigadas e não-irrigadas. As barras de desvios representam o erro-padrão da média de quatro repetições. Epamig, Lavras, MG, 1999. 
tre os tratamentos não foram mantidas com o decorrer dos dias. De uma maneira geral, o fechamento dos estômatos não contribuiu para otimizar a eficiência no uso da água nas plantas sob estresse, como pode ser observado em alguns trabalhos, em que a razão A/E tende a ser superior em condições de deficiência hídrica (Chaves, 1986; During, 1987). As diferenças entre os porta-enxertos para esta razão apareceram somente ao final do experimento, após 12 dias de suspensão da rega, quando as plantas já estavam manifestando sintomas visíveis de estresse, como murcha e necrose nas folhas. Nesta ocasião, a cultivar 'Niágara Rosada' sobre o 1103 Paulsen apresentou valores superiores ao da combinação 'Niágara Rosada' sobre o 101-14, nos dois horários avaliados. Como esse comportamento não foi constante ao longo do período do estresse, torna-se difícil afirmar que o porta-enxerto
1103 Paulsen pode induzir maior tolerância à seca na cultivar 'Niágara Rosada' que o 101-14. O avançado estado de murcha das folhas pode ter interferido nos resultados obtidos.

A eficiência fotoquímica do fotossistema II, obtida através da razão Fv/Fm, somente mostrou diferenças entre os tratamentos irrigado e não-irrigado, no décimo-segundo dia do período experimental. Às doze horas, em condições de déficit hídrico, a cultivar 'Niágara Rosada' sobre o 101-14 apresentou uma menor eficiência fotoquímica do fotossistema II em relação a 'Niágara Rosada' sobre o 1103 Paulsen (Figura 4). Apesar de a combinação 'Niágara Rosada'/101-14 ter mostrado maior sensibilidade do aparato fotossintético à redução da água no solo no final do período experimental, cabe ressaltar que os sintomas de murcha eram visíveis nas folhas da 'Niágara Rosada' enxertada sobre ambos os porta-enxertos.

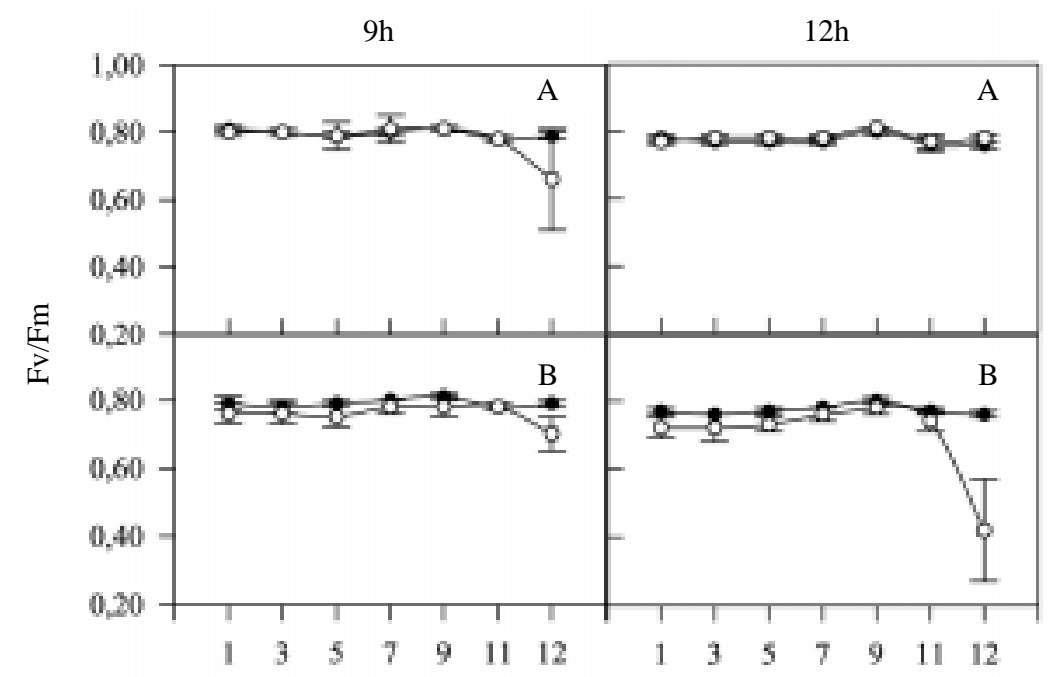

Dias após a suspensão da rega

$\because$ Irrigada $\quad \longrightarrow$ Não-irrigada

Figura 4. Eficiência fotoquímica do fotossistema II [fluorescência variável (Fv)/ fluorescência máxima $(\mathrm{Fm})]$ nos dois horários de avaliação, em mudas de videira cultivar 'Niágara Rosada', sobre dois porta-enxertos 1103 Paulsen (A) e 101-14 (B), durante a suspensão da rega, em plantas irrigadas e não-irrigadas. As barras de desvios representam o erro-padrão da média de quatro repetições. Epamig, Lavras, MG 1999. 


\section{Conclusões}

1. Tanto em condições hídricas ótimas como em baixa disponibilidade de água, as trocas gasosas da cultivar 'Niágara Rosada' não apresentam influência do porta-enxerto.

2. A redução na taxa fotossintética, em condições de deficiência hídrica, está relacionada principalmente ao fechamento estomático.

\section{Referências}

CANDOLFI-VASCONCELOS, M. C.; KOBLET, W.; HOWELL, G. S.; ZWEIFEL, W. Influence of defoliation, rootstock, training system, and leaf position on gas exchange of Pinot noir grapevines. American Journal of Enology and Viticulture, Davis, v. 45, n. 2, p. 173-180, 1994.

CARBONNEAU, A. The early selection of grapevine rootstocks for resistance to drought conditions. American Journal of Enology and Viticulture, Davis, v. 36, n. 3, p. 195-198, 1985.

CHARTZOULAKIS, K.; NOITSAKIS, I.; THERIOS, I. Photosynthesis, plant growth and dry matter distribution in Kiwi fruit as influenced by water deficits. Irrigation Science, Berlin, v. 14, p. 1-5, 1993.

CHAVES, M. M. Effects of water deficit on carbon assimilation. Journal of Experimental Botany, Oxford, v. 42 , p. 1-16, 1991

CHAVES, M. M. Fotossíntese e repartição dos produtos de assimilação em $\boldsymbol{V}$. vinifera. Lisboa: Universidade Técnica de Lisboa, 1986. 220 p. Tese de Doutorado.

CHAVES, M. M.; HARLEY, P. C.; TENHUNEN, J. D.; LANGE, O. L. Gas exchange studies in two Portuguese grapevine cultivars. Physiologia Plantarum, Copenhagen, v. 70 , p. $639-647,1987$

CHAVES, M. M.; RODRIGUES, M. L. Photosynthesis and water relations of grapevines growing in Portugal: response to environmental factors. In: TENHUNEN, J. D.; CATARINO, F. M.; LANGE, O. L.; OECHEL, W. C. (Ed.). Plant response to stress. Berlin: NATO-Advanced Study Institute, 1987. p. 379-390. (Series, G15).

DOWTON, W. J. S.; LOVEYS, B. R.; GRANT, W. J. Nonuniform stomatal closure induced by water stress causes putative non-stomatal inhibition of photosynthesis. New Phytologist, Cambridge, Inglaterra, v. 110, p. 503-509, 1988.
DURING, H. Stomatal responses to alterations of soil and air humidity in grapevines. Vitis, Siebeldingen, v. 26, p. 9-18, 1987.

FARQUHAR, G. D.; SHARKEY, T. D. Stomatal conductance and photosynthesis. Annual Review of Plant Physiology, Palo Alto, v. 33, p. 317-345, 1982.

IACONO, F.; BUCCELA, A.; PETERLUNGER, E. Water stress and rootstock influence on leaf gas exchange of grafted and ungraf grapevines. Scientia Horticulture, Amsterdam, v. 75, p. 27-39, 1998.

KOBLET, W.; CANDOLFI-VASCONCELOS, M. C.; KELLER, M. Effects of training system, canopy management practices, crop load and rootstock on grapevine photosynthesis. Acta Horticulturae, Leuven, v. 427, p. 133-139, 1997.

MOTTARD, G.; NESPOULOUS, J.; MARCOUT, P. Les porte-greffes de la vigne: caractères distinctifs, aptitudes culturales. Paris: Institut des Vins de Consommation Courant, 1963. 36 p. (Bulletin technique d'information des ingénieurs des services agricoles, 182).

NAGARAJAH, S. Physiological responses of grapevines to water. Acta Horticulturae, Leuven, n. 240, p. 249-256, 1989.

PATAKAS, A. Diurnal changes in gas exchange and water relations in field growth grapevines. Acta Horticulturae, Leuven, n. 335, p. 251-256, 1993.

PONI, S.; LAKSO, A. N.; TURNER, J. R.; MELIOUS, R. E. Interactions of crop level and late season water stress on growth and physiology of field-growth concord grapevines. American Journal of Enology and Viticulture, Davis, v. 45, n. 2, p. 252-258, 1994.

POUGET, R. Action de la concentration de la solution nutritive sur quelques caractéristiques physiologiques et technologiques chez Vitis vinifera L. cv. Cabernet Sauvignon: I. Vigueur, rendement, qualité du moût et du vin. Agronomie, Paris, v. 4, n. 5, p. 437-442, 1984.

REGINA, M. de A.; CARBONNEAU, A. Trocas gasosas em Vitis vinifera sob regime de estresse hídrico: I. Caracterização do comportamento varietal. Pesquisa Agropecuária Brasileira, Brasília, v. 31, n. 12, p. 869876, dez.1996.

REGINA, M. de A.; CARBONNEAU, A. Trocas gasosas em Vitis vinifera sob regime de estresse hídrico: III. Ácido abscíssico e comportamento varietal. Pesquisa Agropecuária Brasileira, Brasília, v. 32, n. 6, p. 579-584, jun. 1997.

Pesq. agropec. bras., Brasília, v. 36, n. 10, p. 1221-1230, out. 2001 
SCHULTZ, H. R. Water relations and photosynthetic response of two grapevine cultivars of different geographical origin during water stress. Acta Horticulturae, Leuven, n. 427, p. 251-265, 1997.

SCIENZA, A.; FREGONI, M.; BOSELLI, M. Influenza del portinnesto sulla resistenza stomatica, sul potenziale idrico e sul contenuto di acido abscissico di foglie di 'Barbera'. VigneVini, Bologna, v. 1, p. 39-44, 1980.
SINCLAIR, T. R.; LUDLOW, M. M. Who taught plants thermodynamics? The unfulfilled of plant water potential. Australian Journal of Plant Physiology, East Melbourne, v. 12 , p. 213-217, 1985.

WINKEL, T.; RAMBAL, S. Influence of water stress on grapevines growing in the field: from leaf to whole plant response. Australian Journal of Plant Physiology, Collingwood, v. 20, p. 143-157, 1993. 